\section{Keywords}

Atomic absorption

$\beta$ value
Hydrogen flame

Molecular absorption

Sodium

\title{
高速液体クロマトグラフィーによる洗剤中の けい光増白牏の分析*
}

\author{
中栄 䈚男®，森田まり子，山中 実**
}

(1979 年 8 月 2 日受理)

LiChrosorb RP-18 を固定相に，テトラデシルベンジルジメチルアンモニウム塩を含むメタノール水 溶液を溶離液に用いる逆相イオン対クロマトグラフィーにより, 洗剤中のけい光増白剂 (FWA と略記) を分離定量した．本法によれば，フルキルベンゼンスルホン酸塩などの他の洗郕成分の影響を受けるこ となく FWA を短時間に分離でき，その保持時間より定性分析が簡単に行えた. 又別に作成した検量 線を用いることにより，変動係数 $1.5 \%$ 以下の良好な分析精度で洗剂中の FWA を定量できた.

\section{1 緒言}

現在市販されている衣料用洗剤には，衣料品の白度保 持を目的としてFWA が配合されている.FWA の種類 が異なれば纎維に対する増白効果, 化学的な安定性など も異なり，FWA の分析は，衣料用洗剂の性能を評価す るらえで重要な項目の一つとなっている.

従来 FWA の分析には, 薄層クロマトグラィー1) 4), スポット試験(1), 洗浄試験 ${ }^{1)}$, 紫外吸収スペクトル法(1)35), けい光スペクトル法1)などを組み合わせて用いるのが一 般的であった. 又, シリカゲルを固定相に用いる高速液 体クロマトグラフィー6)7) も検討されている. しかし， 洗剂に使用されるけい光増白剤は種類も多く，いずれる あまり実用的な分析法とはいい難い，そこで著者らは， 高速液体クロマトグラフィー (HSLC と略記) による洗 凬成分の分析の一環として，洗剤中の FWA をなんらの 前処理も施さず，迅速に定性・定量分析することを企画 した.

* 高速液体クロマトグラフィーによる洗剂成分の分析 (第 5 報). 前墭は中栄篤男，降矢一美，山中 实 : 日化，1978，708

** 花王石瞼 (株) 杤木研究所 : 杤木県芳賀郡市貝町赤羽 2606
本報で対象とした FWA は,いずれもスルホン酸基を 有する水溶性の高いイオン性物質であり，イオン交換法 による分離分析が考兄られるが，いずれも分子量が大き く，カラムからの溶出に長時間を要することが予想され る。そこで，陽イオン界面活性剤を添加した溶離液を用 い，逆相分配型の充てん剂を固定相とするイオン対クロ マトグラフィーの適用を試み良好な結果を得た。

\section{2 実験}

\section{1 装 置}

使用した装置は，日立製作所製 635 形高速液体クロマ トグラフのボンプ，高压サンプリングバルブ，カラム用 循環恒温そう，外とう管を有するステンレス製 カラム （内径 $4 \mathrm{~mm}$ ，長さ $150 \mathrm{~mm}$ ) と島津製作所製 のけい光 検出器 FLD-1 形 \{ランプ: $(300 \sim 400) \mathrm{nm}$ 励起用, EM-4 フィルター：(450〜800) nm 使用\}, データ処理 装置クロマトパック $\mathrm{E} 1 \mathrm{~A}$, 記録計 $\mathrm{R}-11$ を組み合わせ たものである.

\section{2 試 薬}

カラム充てえ刘 : E. Merck 社製 LiChrosorb RP-18 $(5 \mu \mathrm{m})$ を使用した。

硝酸テトラデシルベンジルジメチルフンモニウム (BzAN と略記) : 花王石撂製の塩化テトラデシルベンジ ルジメチルフンモニウム $\left(\mathrm{C}_{12}: 2 \%, \mathrm{C}_{14}: 95 \%, \mathrm{C}_{16}\right.$ : 
Table 1 Chemical structures of fluorescent whitening agents

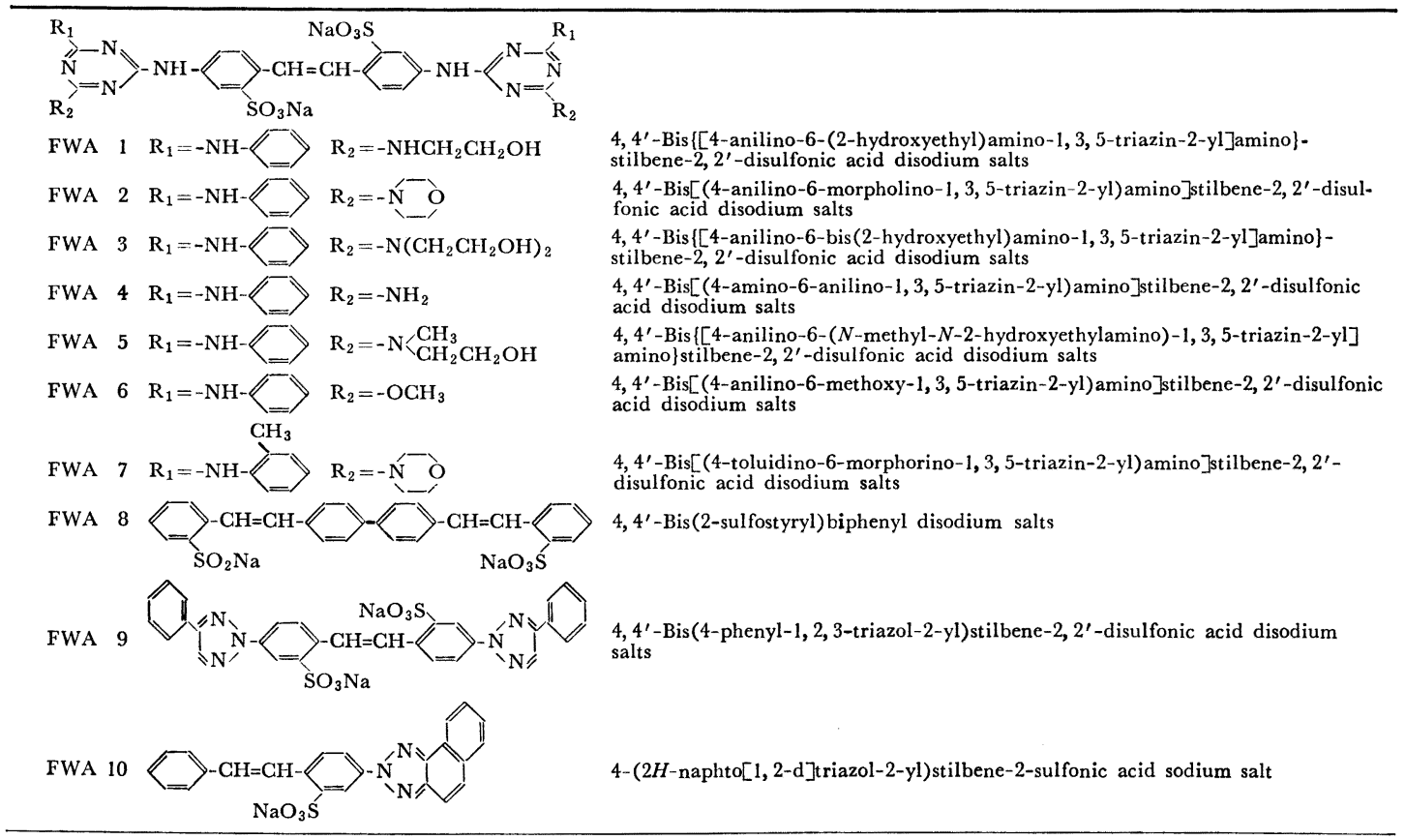

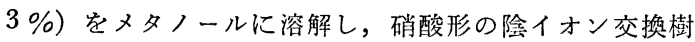
脂カラムを通し, カラム溶出液を留去, 減圧乾燥したも のを使用した。なお調製した BzAN 中には，塩化物イ オンが含まれていないことを硝酸銀溶液滴下試験により 確認した.

けい光増白剤 : 日本化薬, 住友化学, Giba-Geigy 製 の市販品をそのまま使用した。 なお Table 1 にその化 学構造式を示す.

他の試薬は，市販特級品及て: 1 級品をそのまま使用し た.

\section{3 カラムの調製}

LiChrosorb RP-18 $1.5 \mathrm{~g}$ とポリオキシェチレンドデ シルェーテル(平均 $\mathrm{EO}$ 付加モル数 10) $0.5 \mathrm{~g}$ を $50 \mathrm{ml}$ のビーカーに採取し，四塩化炭素 $10 \mathrm{ml}$ を加兄，超音波 洗浄器を用いてよく分散させスラリー状とする. スラリ 一状の充てん剤を空カラムに接続したパッカー（内容積 $10 \mathrm{ml}$ ) に移し, 加圧溶媒にメタノールを用い約 $450 \mathrm{~kg} /$ $\mathrm{cm}^{2}$ の高圧下で充てんする.な拈本法で得たLiChrosorb RP-18 カラムは，多環芳香族化合物を分析したところ 平衡スラリー法で作成した同一充てん剤のカラムと同程 度の性能を有していた.

\section{3 結果及び考察}

\section{1 分離条件の検討}

イオン対クロマトグラフィーに拈いては，溶離液中に
添加する対イオンの種類と濃度, 溶離液の組成, カラム 温度が分離に対して重要なファクターとなる．本報で は，水溶性の高いFWA の対イオンとして,陽イオン界 面活性剤である $\mathrm{BzAN}$ を選定し, 分離条件の検討を行 った.な和陽イオン界面活性剂を塩素形で用いたので は, 装置のステンレス配管部の腐食が進行し, カラムの フィルター部の目詰まりやカラムの劣化が顕著となり, 再現性の良好な分離結果を得ることができなかった。

溶離液中の $\mathrm{BzAN}$ 濃度を変化させ，FWA の保持時 間に与える影響を 調べた. その結果を Fig. 1 に示す が， $\mathrm{BzAN}$ 濃度が $0.5 \mathrm{w} / \mathrm{v} \%$ までは, $\mathrm{BzAN}$ 濃度の 上昇につれ FWA の保持時間は増大し, BzAN 濃度が $0.5 \mathrm{w} / \mathrm{v} \%$ 以上になると,カラムからの溶出の速い FWA の保持時間はほぼ一定となり, カラムからの溶出の遅い FWA の保持時間は減少する. 又 FWA 8, FWA 9 は, $\mathrm{BzAN}$ 濃度の変化によって他の FWA と溶出順序が逆 転する．ここでは，FWA の相互分離及び分析時間を考 慮し, 溶離液中の $\mathrm{BzAN}$ 濃度は $0.25 \mathrm{w} / \mathrm{v} \%$ とした. 溶離液中の水分含量を変化させ，FWA の保持時間に 与える影響を調べた，その結果を Fig. 2 に示すが，溶 離液中の水分含量が増すにつれて FWA の保持時間は増 大する. 特に保持時間の長いFWA ほどその遅れは顕著 である. 又カラム温度の上昇は, Fig. 3 に示すように FWA の溶出を速め，カラム温度を一定にすることは， 


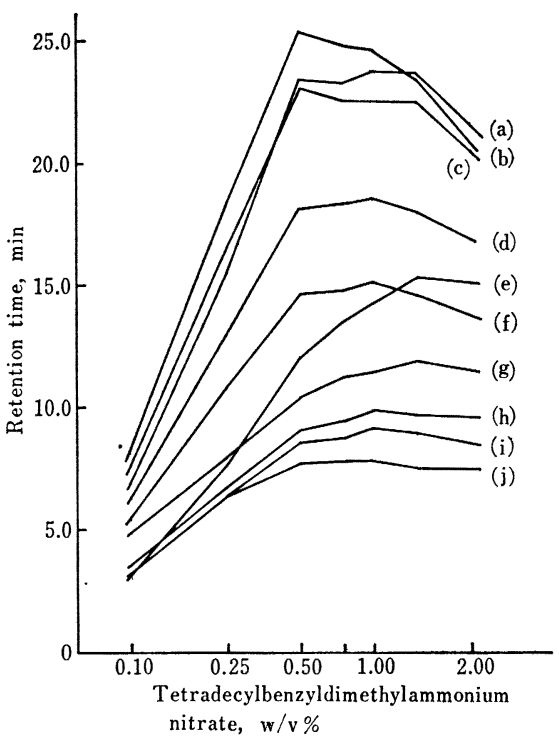

Fig. 1 Effect of tetradecyldimethylammonium nitrate concentration on retention time of fluorescent whitening agents

Conditions-Column : LiChrosorb RP-18 $5 \mu \mathrm{m}(4 \mathrm{~mm}$ i. d. $\times 150 \mathrm{~mm}$ ), eluent : methanol/water $(86: 14)$, flow rate $: 1.0 \mathrm{ml} / \mathrm{min}$, pressure $: 100 \mathrm{~kg} / \mathrm{cm}^{2}$, column temp. : $40^{\circ} \mathrm{C}$; (a) FWA 9; (b) FWA 7; (c) FWA 2; (d) FWA 6; (e) FWA 8; (f) FWA 5; (g) FWA 10; (h) FWA 4; (i) FWA 1; (j) FWA 3

再現性の良好な分析結果を得るためには不可欠である. ここでは，分析時間を考虑し，溶離液中の水分含量を $14 \mathrm{v} / \mathrm{v} \%$ 及びカラム温度を $40^{\circ} \mathrm{C}$ とした。 なお，Fig. 4 に FWA の標準クロマトグラムを示す。

\section{2 洗凨中の FWA の分析}

3.2.1 定性分析 市眅の衣料用粉末洗剂約 $200 \mathrm{mg}$ にメタノール $100 \mathrm{ml}$ を加え, FWA を溶解させる. 硫 酸ナトリウムなどの無機ビルダーの沈殿した上澄をマイ クロシリンジに $10 \mu 1$ 採り，高圧サンプリングバルブを 用いて試料を分析カラムに注入し，得られたクロマト グラムの保持時間より FWA の定性分析を行った。 そ の結果，現在市販されている衣料用洗剂には，FWA 2， FWA 7，FWA 8 が主に使用されていることが分かっ た. 従って，これらのFWA について定量分析を行うこ とにした.

3.2.2 検量線の作成 $100 \mathrm{ml}$ 中に $100 \mu \mathrm{g}$ の FWA 8 と $600 \mu \mathrm{g}$ の FWA 2 あるいは FWA 7 を含むメタ ノール溶液を調製し，検量線作成用標準溶液とする。こ の標準溶液をマイクロシリンジで正確に $5 \mu \mathrm{l}$ から $20 \mu \mathrm{l}$

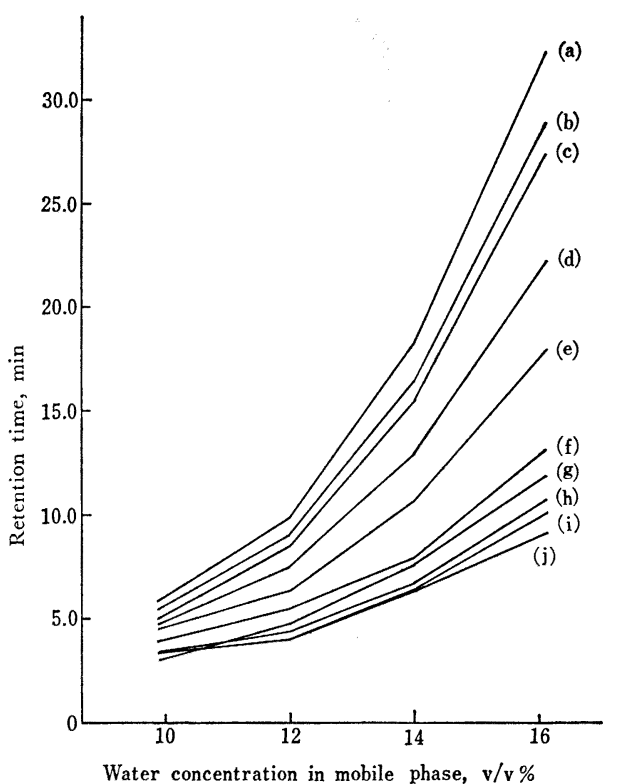

Fig. 2 Effect of water concentration on the retention time

Conditions are the same as indicated in Fig. 1 except for the eluent $(0.25 \mathrm{w} / \mathrm{v} \%$ tetradecylbenzyldimethylammonium nitrate in methanol/water). (a) FWA 7; (b) FWA 2; (c) FWA 9; (d) FWA 6; (e) FWA 5; (f) FWA 10; (g) FWA 8; (h) FWA 4; (i) FWA 1; (j) FWA 3

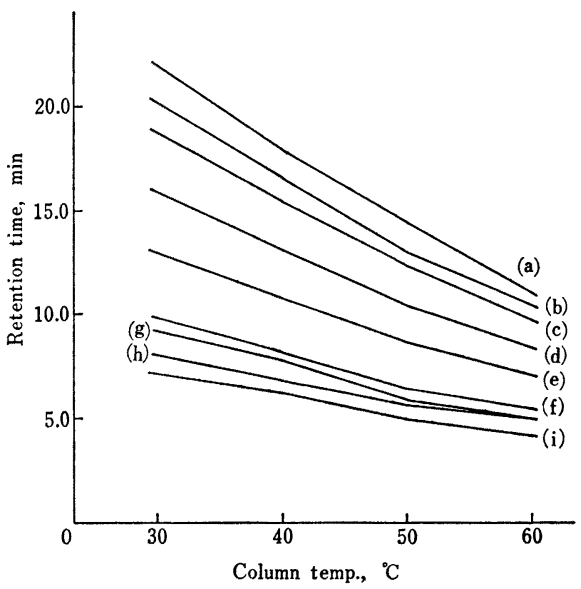

Fig. 3 Effect of column temperature on the retention time

Conditions are the same as indicated in Fig. 2 except for the eluent $\{0.25 \mathrm{w} / \mathrm{v} \%$ tetradecylbenzyldimethylammonium nitrate in methanol/water $(86: 14)\}$ and column temperature. (a) FWA 7; (b) FWA2; (c) FWA 9; (d) FWA 6; (e) FWA 5; (f) FWA 10; (g) FWA 8; (h) FWA 4; (i) FWA 1 and 3 


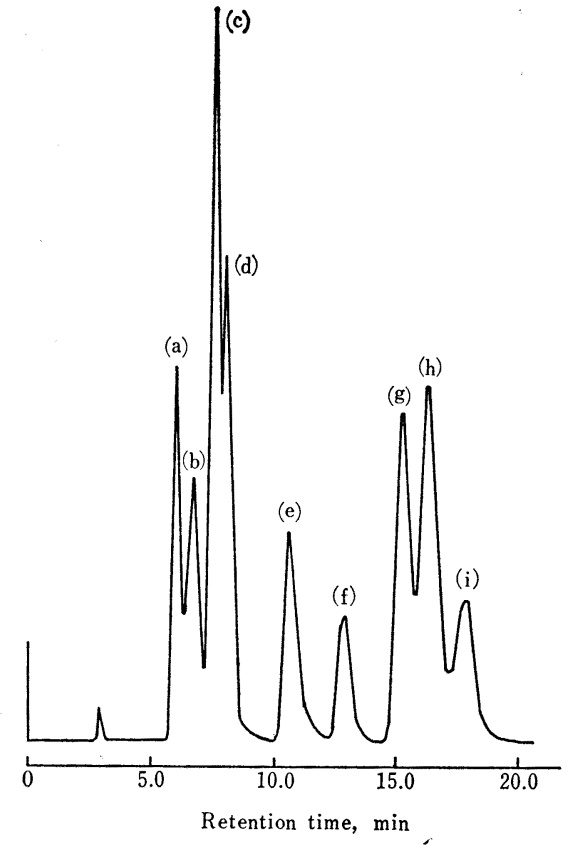

Fig. 4 Typical chromatogram of a standard mixture of fluorescent whitening agents

Conditions-Column : LiChrosorb RP- $185 \mu \mathrm{m} \mathrm{(4} \mathrm{mm}$ i. d. $\times 150 \mathrm{~mm}$ ), eluent : $0.25 \mathrm{w} / \mathrm{v} \%$ tetradecylbenzyldimethylammonium nitrate in methanol/water (86: 14), flow rate $: 1.0 \mathrm{ml} / \mathrm{min}$, pressure $: 100 \mathrm{~kg} / \mathrm{cm}^{2}$, column temp. : $40^{\circ} \mathrm{C}$, detector : Shimadzu FLD-1 $\left\{E_{\mathrm{x}}:(300 \sim 400) \mathrm{nm}, E_{\mathrm{m}}:(450 \sim 800) \mathrm{nm}\right\}$, sample: $100 \mathrm{ng}$ of each FWA except for $10 \mathrm{ng}$ of FWA 8 ; (a) FWA 1 and 3; (b) FWA 4; (c) FWA 8; (d) FWA 10; (e) FWA 5; (f) FWA 6; (g) FWA 9; (h) FWA 2; (i) FWA 7

まで $5 \mu \mathrm{l}$ ごとに採取し，分析カラムに注入し，得られる ピーク面積を用いて検量線を作成した. その結果，いず れの検量線も原点を通る直線となった。

3.2.3 洗剈中の FWA の定量 FWA を含まない 粉末洗郕約 $200 \mathrm{mg}$ に一定量の FWA 2 及び FWA 8 を 含むメタノール溶液を加え,メタノールを堿圧留去して FWA 含有洗剤とする，この洗剤に約 $70 \mathrm{ml}$ のメタノ ールを加克，スターラーで約 5 分間かくはんし，メタ， ールに不溶の無機ビルダーをろ別した後，メタノールで 正確に $100 \mathrm{ml}$ とする. この溶液 $10 \mu \mathrm{l}$ を正確にマイク ロシリンジに採り，検量線作成時と同様に分析し，先に 求めた検量線より FWA 量を算出し回収率を求める. その結果を Table 2 と示すが，FWA 2 及び FWA 8 とも回収率は良好であり，本分析に用いたメタノール抽 出法で粉末洗剤より FWA を定量的に回収できることが 明らかとなった．又，市販の粉末洗剤を分析した結果を
Table 3 及び Table 4 に示すが，いずれもクロマトグ ラム上に妨害成分は認められず，再現性も良好であっ た. なお，Fig. 5 に粉末洗剤中の FWA を定量した際 得られたクロマトグラムの1例を示す.

Table 2 Determination of fluorescent whitening agents in a detergent ${ }^{\dagger}$

\begin{tabular}{cccc}
\hline Compound & Added $(\mathrm{mg})$ & Found $(\mathrm{mg}) \dagger \dagger$ & Recovery(\%) \\
\hline FWA 2 & 0.530 & 0.538 & 101.5 \\
FWA 8 & 0.390 & 0.382 & 97.9 \\
\hline
\end{tabular}

$\dagger$ Detergent used - Sodium sulfate : $44.5 \%$, sodium alkylbenzenesulfonates : $20.8 \%$, sodium triphosphate : $21.0 \%$, sodium silicate : $10.2 \%$, sodium carbonate: $1.2 \%$, soap : $1.2 \%$, sodium salt of carboxymethylcellulose : $1.1 \%$; $\dagger$ Mean of duplicatc analyses

Table 3 Precision of the determination $\dagger$

\begin{tabular}{cccc}
\hline Compound & Found(\%) $\dagger \dagger$ & C. V. $(\%)$ & Range(\%) \\
\hline FWA 7 & 0.159 & 1.23 & $0.156 \sim 0.163$ \\
FWA 8 & 0.422 & 1.43 & $0.410 \sim 0.430$ \\
\hline
\end{tabular}

$\dagger$ This detergent contains FWA 7 and 8 ; $\dagger \dagger$ Mean of 11 replicated analyses

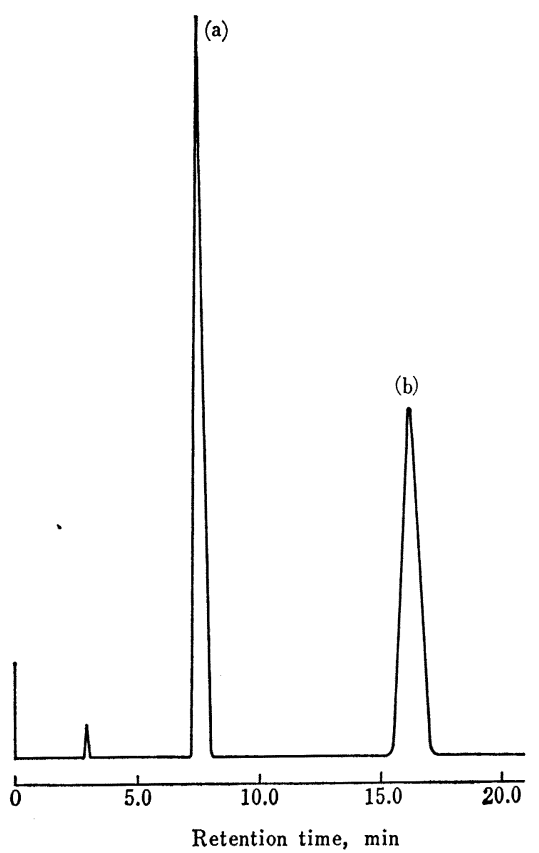

Fig. 5 Typical chromatogram of fluorescent whitening agents in a commercial detergent

Conditions are the same as indicated in Fig 4. (a) FWA 8; (b) FWA 2 
Table 4 Determination of fluorescent whitening agents in several commercial detergents

\begin{tabular}{ccc}
\hline Sample & Compound & Found(\%)† \\
\hline A & FWA 7 & 0.37 \\
& FWA 8 & 0.10 \\
B & FWA 7 & 0.24 \\
& FWA 8 & 0.16 \\
C & FWA 2 & 0.79 \\
D & FWA 2 & 0.66 \\
& FWA 8 & 0.13 \\
E & FWA 2 & 0.36 \\
& FWA 8 & 0.16 \\
\hline
\end{tabular}

$\dagger$ Mean of duplicate analyses

$$
4 \text { 結 語 }
$$

LiChrosorb RP-18 を固定相に，陽イオン界面活性剂 を含むメタノール水溶液を溶離液に用いるイオン対クロ マトグラフィーにより, 洗剂中の FWA を分離定量し た.アルキルベンゼンスルホン酸塩なぞの外の洗剤成分 は，いずれも本報で使用したけい光検出器に応答せず， カラム溶出液中の FWA を選択的に高感度に 測定でき た. (5〜20)ng の範囲で作成した FWA 8 の検量線及び $(30 \sim 120) \mathrm{ng}$ の範囲で作成した FWA 2, FWA 7 の検量 線は，いずれも原点を通る直線となった，又本法を用い ることにより，洗剤中の FWA を変動係数 $1.5 \%$ 以下 の良好な分析精度で定量することができた.

\section{文献}

1) P. Stensby : Soap Chem. Spec., 43, 96 (1967).

2) J. Schulze, T. Polcaro, P. Stensby : Soap Cosmet. Chem. Spec., 50, 46 (1974).

3) G. Lehmann, M. Becker-Klose : Tenside Detergents, 13, 7 (1976).

4) H. Theidel, G. Schmitz : J. Chromatogr., 27, 413 (1967).

5) G. Weis : Tenside Detergents, 12, 43 (1975).

6) D. Kirkpatrick : J. Chromatogr., 121, 153
(1976) .

7) D. Kirkpatrick : J. Chromatogr., 139, 168 (1977).

$$
\hat{n}
$$

Separation and determination of fluorescent whitening agents in detergents by high speed liquid chromatography. (Analysis of detergents for ingredients by high speed liquid chromatography. V.) Atsuo Nakae, Mariko Morita and Makoto Yamanaka (Tochigi Research Laboratories, Kao Soap Co., Ltd., 2606, Akabane, Ichikai-machi, Haga-gun, Tochigi)

Ten fluorescent whitening agents (FWA), stilbene derivatives, listed in Table 1 were separated by reversed phase ion-pair chromatography using tetradecylbenzyldimethylammonium nitrate (BzAN) as a pairing ion. Retention times of FWA were affected by the eluent composition and column temperature. The recommended conditions were as follows; column: LiChrosorb RP-18 $5 \mu \mathrm{m}, 4 \mathrm{~mm}$ i. d. $\times 150 \mathrm{~mm}$, eluent: $0.25 \mathrm{w} / \mathrm{v} \%$ BzAN in methanol/water $(86: 14)$, flow rate: $1.0 \mathrm{ml}$ / min, pressure: $100 \mathrm{~kg} / \mathrm{cm}^{2}$, column temperature: $40^{\circ} \mathrm{C}$. FWA in the column effluent was monitored with Shimadzu FLD-1 fluorescent detector $\left\{E_{\mathrm{x}} \cdot:(300 \sim 400)\right.$ $\left.\mathrm{nm}, E_{\mathrm{m}}:(450 \sim 800) \mathrm{nm}\right\}$ equipped with Shimadzu datalyzer Chromatopac-ElA. By the qualitative analysis, FWA 2, 7 and 8 were found in commercial detergents. The calibration curves for FWA 2 and 7 were linear within a range of $(30 \sim 120) \mathrm{ng}$, and that of FWA 8 was $(5 \sim 20)$ ng. Other ingredients such as alkylbenzenesulfonates do not interfere with the separation and the determination. By the proposed method, FWA in detergents was determined easily and the relative standard deviation was within $1.5 \%$.

(Received Aug. 2, 1979)

\section{Keywords}

\section{Detergent}

Fluorescent whitening agent

High speed liquid chromatography

Ion-pair chromatography

Tetradecylbenzyldimethylammonium nitrate 